\title{
THE RISK MANAGEMENT IN THE SELECTED COMPANY
}

\author{
Radim Pavelek
}

\begin{abstract}
The paper deals with risk management in the organization SFINX in the Czech Republic. Firstly, there is a literature review of risk management. Secondly, there is a used methodology part. In this part is discussed SWOT analysis and risk matrix with a modified score method. In the questionnaire, the risks were divided into A) Production risks (technical, social, purchasing, distribution), B) Economic risks, C) Market risks, D) Financial risks, E) Political risks. The probability of the occurrence of the risk was assessed: value one for the lowest occurrence, while value five for the highest, the most probable occurrence. The impact was assessed similar: number one for the least serious impact, while number five for the most severe effect. Based on the questionnaire were evaluated the most critical risks that threaten the organization from the perspective of employees. The resulting risk is determined by the product of the probability and impact of the risk. In this paper, risk was determined by multiplying the average values of probability and impact of the selected risk. The averages of these two quantities were obtained based on a questionnaire survey. Then the selected risks were entered on the map, for the risks placed in the significant risk values quadrant and the critical risk values quadrant, the scoring method recommends making proposals to reduce them. In this work, the technique will be adjusted so that the probability and impact will be evaluated from 1 to 5. In the end of the paper, there are presented the results based on the mentioned methodology - the most severe risks that may threaten the organization. Finally, there is recommendations for the organization.
\end{abstract}

Keywords: risk, questionnaire, SWOT analysis, risk matrix, score method

\section{INTRODUCTION}

Risk intrinsically belongs to our world. Furthermore, risks affect the life of the company; therefore, risk management is needed. Risk management enables an organization to identify, analyse, and evaluate hazards that could seriously endanger the company. After their evaluation, the company could propose measures that reduce the risk. However, not all actions operate in practice; therefore, after the measure has been implemented, it is necessary to check whether it works, if not, to come up with a unique solution. Gratitude to risk management, the organization, could prepare in the future for what could threaten it (economic crisis or poorly chosen strategy and related problems etc.). If an enterprise knows what it could endanger, it could respond more flexibly to future challenges and avoid any financial loss, loss of market position, or even its disappearance.

This paper deals with risk management in the selected organization, the SFINX factory in Holešov, which falls under Nestlé Česko, s.r.o. In the methodological part are introduced methods that will be used. With the advice of a questionnaire, a modified scoring method, and a risk matrix, we will present the most serious risks that may endanger a given company. For the most severe threats, possible proposals to reduce them will be presented. (Walter, 2013) 


\section{METHODOLOGY}

The aim of this paper is to assess the risks that may threaten the organization. The following methods are used - questionnaire, SWOT analysis and Risk matrix with the modified scoring method.

\subsection{Questionnaire}

The questionnaire survey is one of the most popular methods of research; it is a mass gathering of data from interviewed persons. In the questionnaire, the risks were divided into A) Production risks (technical, social, purchasing, distribution), B) Economic risks, C) Market risks, D) Financial risks, E) Political risks. The probability of the occurrence of the risk was real: value one was the lowest occurrence, while value five was the highest, the most probable occurrence. The impact was real: number one was for the least serious impact, while number five was for the most severe effect. Based on the questionnaire were evaluated the most critical risks that threaten the organization from the perspective of employees. (Litschmannová, 2009)

Tab. 1 - The probability of occurrence. Source: Litschmannová (2009)

$\begin{array}{cc}\text { Classification } & \text { Verbal expression } \\ 1 & \text { Practically unlikely } \\ 2 & \text { Not very likely } \\ 3 & \text { Occasionally } \\ 4 & \text { Likely to frequent } \\ 5 & \text { Very frequent }\end{array}$

Tab. 2 - Impact on risk. Source: Litschmannová (2009)

$\begin{array}{cc}\text { Classification } & \text { Verbal expression } \\ 1 & \text { Negligible } \\ 2 & \text { Low } \\ 3 & \text { Medium } \\ 4 & \text { Serious } \\ 5 & \text { Critical }\end{array}$

\subsection{SWOT analysis}

SWOT analysis is a universal tool that maps and analyses a given phenomenon (e.g., a particular state or project, etc.). The analysed subject is examined from Strengths, Weakness, Opportunities and Threats points of view (Badal, 2019).

\subsection{Risk matrix with modified Score method}

The scoring method includes the risk identification phase, the risk assessment, and the design of the risk reduction measures. The technique makes it possible to evaluate risks that are not precisely numerically expressed. This method deals with lists of hazards from the four most crucial areas - technical, financial, personnel and business risks. (Lacko, n.d.)

Tab. 3 - Risk Matrix. Source: Lacko (n.d.)

\begin{tabular}{|c|c|c|c|c|c|c|}
\hline & & \multicolumn{5}{|c|}{ Impact (D) } \\
\hline & & 1 & 2 & 3 & 4 & 5 \\
\hline \multirow{5}{*}{ 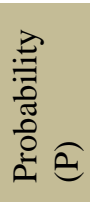 } & 5 & 5 & 10 & 15 & 20 & 25 \\
\hline & 4 & 4 & 8 & 12 & 16 & 20 \\
\hline & 3 & 3 & 6 & 9 & 12 & 15 \\
\hline & 2 & 2 & 4 & 6 & 8 & 10 \\
\hline & 1 & 1 & 2 & 3 & 4 & 5 \\
\hline
\end{tabular}

Table 3 shows the risk matrix - it is a $5 \times 5$ matrix, the probability and impact of risks is evaluated from 1 to 5 , the higher the number, the higher the likelihood and impact of the risk. 
The resulting risk is determined by the product of the probability and impact of the risk. In this paper, risk will be determined by multiplying the average values of probability and impact. The averages of these two quantities will be obtained based on a questionnaire survey.

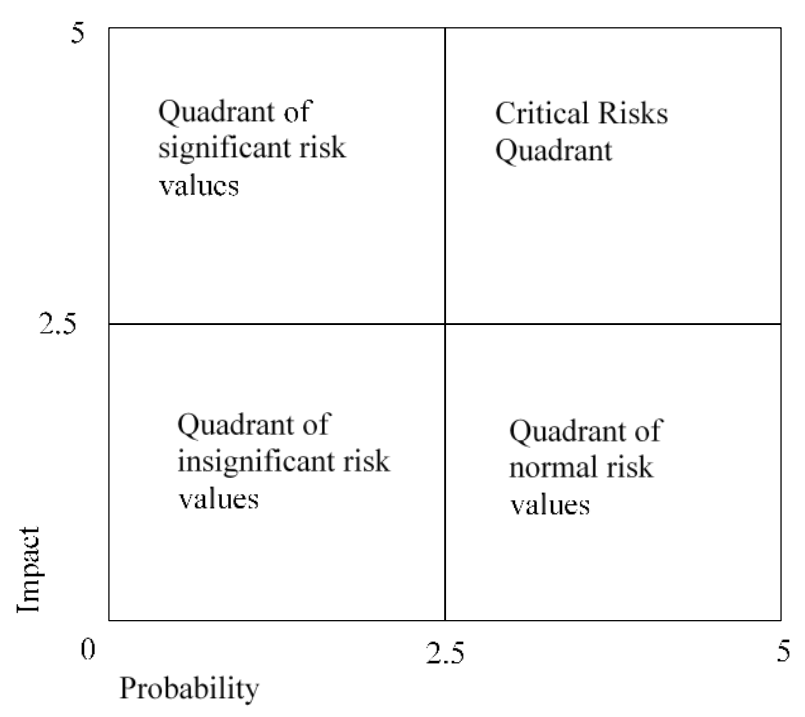

Fig. 1 - Risk map. Source: Lacko (n.d.)

A risk map is used to represent risks graphically. On the horizontal axis, there is the possibility of occurrence (probability) of risk; the vertical axis represents the impact assessment. Based on these two values, the risk is entered on the map. The entire plan is divided into four quadrants: the insignificant risk values quadrant, the normal risk values quadrant, the significant risk values quadrant, and the critical risk values quadrant. For the risks placed in the last two quadrants, the method recommends making proposals to reduce them. In this work, the technique will be adjusted so that the probability and impact will be evaluated from 1 to 5 .

\section{RESULTS}

\subsection{Questionnaire}

Based on the questionnaire was evaluated the most severe risks that threaten the organization from the perspective of employees. The survey dealt with the risks as they were divided above A) Production risks (technical, social, purchasing, distribution), B) Economic risks, C) Market risks, D) Financial risks, E) Political risks. Fifty-four respondents participated in the questionnaire survey.

In terms of position, the most frequent respondents in the questionnaire were operators, followed by technical-economic workers and production masters. The least numerous respondents were management staff. In terms of the length of employment, the most frequent respondents were workers with a period of work between three and five years. However, the proportion of respondents from individual groups was very balanced.

When comparing the most severe risks from individual groups, most respondents stated that the most critical risks were supply risk $(\mathrm{R}=16$ approximately, from the category of purchasing risks of production) assessed as probable to frequent (4) with serious (4) from economic risks $(\mathrm{R}=16$ approximately). 


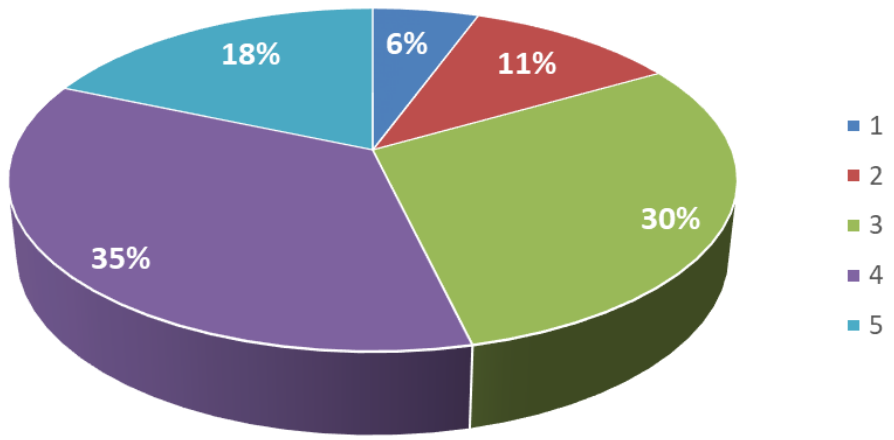

Fig. 2 - Probability of supply risks. Source: own research

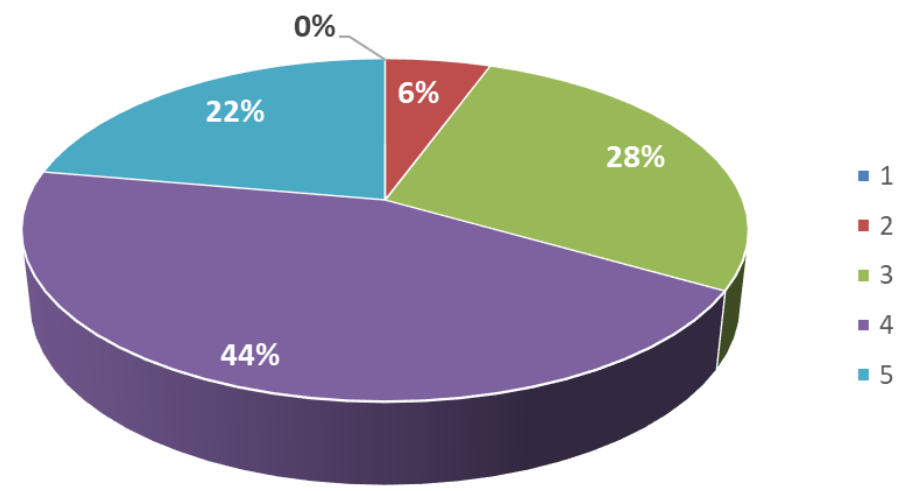

Fig. 3 - Evaluation of the impact of supply risks by respondent. Source: own research

\subsection{SWOT analysis}

In the SWOT analysis are first described internal factors that influence the organization strengths, and weaknesses. The following are external factors that are related to the environment - opportunities and threats.

Tab. 4 - SWOT analysis. Source: own research

$\begin{array}{ll}\text { Strengths } & \text { Weakness } \\ \text { Wide range of quality products } & \text { High staff turnover } \\ \text { Traditional marks } & \text { Increasing price of products } \\ \text { ISO certificate } & \text { Increasing operating costs } \\ \text { Important employer in the region } & \text { Obsolete machinery } \\ \text { Opportunities } & \text { Threats } \\ \text { New markets abroad } & \text { New competition } \\ \text { Cooperation with new suppliers } & \text { Loss of customers } \\ \text { Healthy lifestyle trend } & \text { Cost increases linked to stricter EU standards } \\ \text { Increasing standard of living of the inhabitants } & \text { Economic crisis } \\ \text { Increasing emphasis on business ethics } & \text { Increasing price of raw materials needed for production }\end{array}$

\subsection{Risk Matrix with modified Score method}

For the scoring method, we first compiled a table of risk factors, assigning a sequence number to each element. For the valuation of risks, we set values from 1 to 5 for both the possibility of risk occurrence and its impact (as in the questionnaire survey).

The resulting risk ranged between 1 and 25. The calculation can be imagined in the following risk matrix with a modified scoring method. From the individual probabilities evaluated from the questionnaire, we made their average; for the impacts being assessed, we did the same. We multiplied the standards together and got the average overall risk. We divided the overall risk 
into three groups: acceptable (low, green in the matrix), conditionally acceptable (medium, yellow in the matrix) and unacceptable (high, red in the matrix).

Tab. 5 - Risk matrix. Source: own research

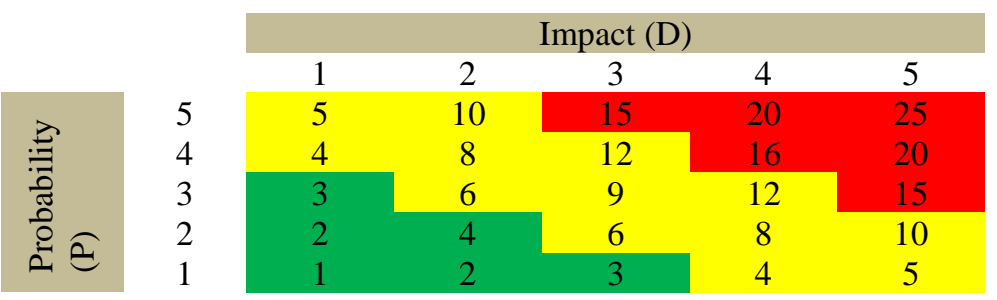

The most serious risk factors were: technical, supply, subcontractors, cost risks, and competitive pricing policy. These risks are displayed in the Risk Map in the Critical Risk Value quadrant. See figure below.

Tab. 6 - Valuation of supply risk factor. Source: own research

\begin{tabular}{|l|c|}
\hline Risk quantification by company employees & Score (average) supply factor \\
\hline (P) Possibility of occurrence & 3,5 \\
\hline (D) Impact & 3,83 \\
\hline Risk assessment $=$ P $\times$ D & $13,41 \approx 13$ \\
\hline
\end{tabular}

According to the risk matrix, these several serious risks are broken down as follows: (a) supply risks - between conditionally acceptable and unacceptable risks, closer to unacceptable risks; (b) technical risks (as part of production risks), cost, price policy of competition on the border of conditionally acceptable risks; (c) subcontracting risks - in conditionally acceptable risks.

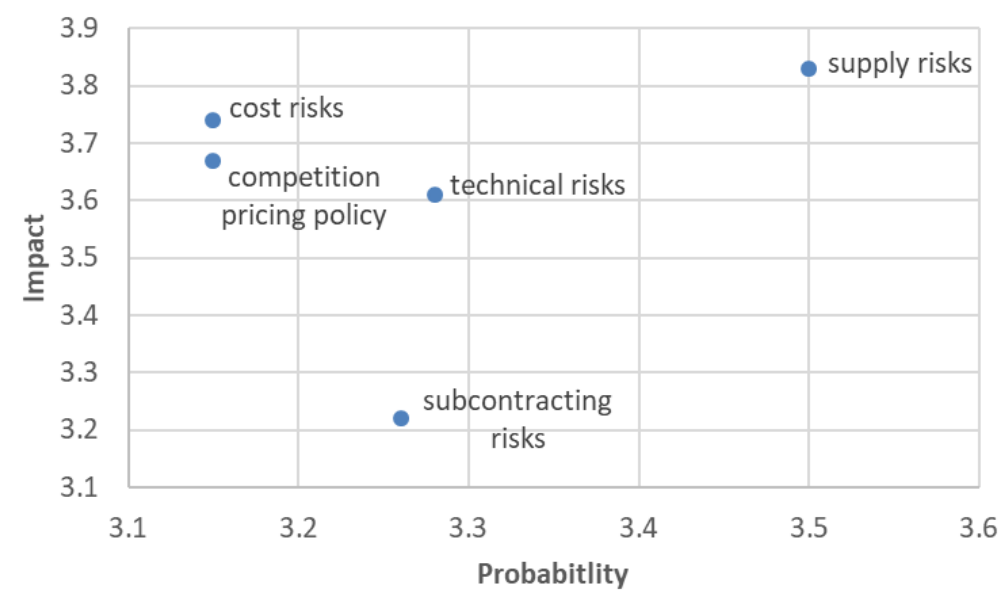

Fig. 4 - Risks in the quadrant of critical risk values in the risk map. Source: own research

\section{DISCUSSION AND CONCLUSION}

This paper deals with risk management in the selected organization. First, a selected organization was introduced - the SFINX plant in Holešov. Then we switched to the methods used in the paper. The first questionnaire survey was used, the aim of which was to find out what risks the company employees evaluate as the most serious. Then we went to the SWOT analysis, where we assessed the internal and external factors that affect the company. Lastly, we used a modified scoring method in which we evaluated the results obtained by a questionnaire survey. It was found that employees consider the supply risks, technical risks, cost risks, competition pricing policy, and subcontracting risks to be the most serious risks for the company. Based on these results, proposals have been proposed to reduce them. 
Tab. 7 - Risk reduction proposals. Source: own research

\begin{tabular}{|c|c|c|}
\hline Risk factor & Precaution suggestion & Responsibility \\
\hline 1. technical & $\begin{array}{l}\text { 1. Gradual innovation of obsolete } \\
\text { production lines. } \\
2 \text {. Extension of existing insurance against } \\
\text { production failure. }\end{array}$ & $\begin{array}{l}\text { 1. Head of Technical Department } \\
\text { 2. Factory management }\end{array}$ \\
\hline 6. supply & $\begin{array}{l}\text { 1. Optimization of insurance stocks } \\
\text { according to orders. } \\
\text { 2. Ensuring spare parts of machines. }\end{array}$ & Head of Logistics Department \\
\hline 7. subcontractors & $\begin{array}{l}\text { Securing raw materials from multiple } \\
\text { sources - diversification of inputs. }\end{array}$ & Head of Logistics Department \\
\hline 11. costs (cost risks) & Quantity discounts. & Factory management \\
\hline $\begin{array}{l}\text { 17. competition } \\
\text { pricing policy }\end{array}$ & $\begin{array}{l}\text { 1. Improving the quality of their products. } \\
\text { 2. Building a good reputation. }\end{array}$ & $\begin{array}{l}\text { 1. Head of the Quality } \\
\text { Management Department } \\
\text { 2. Management of company }\end{array}$ \\
\hline
\end{tabular}

\section{References}

Badal, T. (2019). SWOT analýza. Retrieved from http://user.mendelu.cz/xbadal/Studijni\%20opory/Hospodarska\%20informatika/Stud_m at/SWOT\%20anal\%FDza.pdf

Lacko, B. (n.d.). Ǩizení rizik a př́ležitostí $v$ projektech. Retrieved from http://www.projektmanazer.cz/kurz/soubory/modul-g/g5.pdf

Litschmannová, M. (2009). Máme dotazniky. A co dál? Retrieved from https://homel.vsb.cz/ lit40/SKOMAM_09.PDF

Walter, M. (2013). SFINX Holešov: 150 let výroby cukrovinek. Retrieved from www.nestle.cz/cz/media/tiskove-zpravy/sfinx-holesov-150-let-vyroby-cukrovinek\#

\section{Contact information}

\section{Radim Pavelek}

Tomas Bata University in Zlín, Faculty of Logistics and Crisis Management

Studentské nám. 1532, 68601, Uherské Hradiště, Czech Republic

E-mail: r_pavelek@utb.cz

ORCID: 0000-0002-4476-1771

doi: 10.7441/dokbat.2019.085 